\title{
Dampak Aksi Terorisme Dan Upaya Deradikalisasi Penanganan Atas Kondisi Sosial Ekonomi
}

\author{
Nugi Mohammad Nugraha ${ }^{1}$, Vincentia Wahju Widajatun ${ }^{2}$, Abdul Rozak ${ }^{3}$ \\ ${ }^{1}$ Universitas Widyatama, Bandung, nugi.mohammad@widyatama.ac.id \\ ${ }^{2}$ Universitas Widyatama, Bandung, vincentia.wahju@ widyatama.ac.id \\ ${ }^{3}$ Universitas Widyatama, Bandung, abdul.rozak@widyatama.ac.id
}

\begin{abstract}
Abstrak
Pemerintah dan masyarakat meyakini bahwa fenomena terorisme belum akan hilang dengan begitu mudahnya. Perlu upaya dalam menangani permasalahan ini secara sistematis dan komprehensif. Tujuan dari penelitian ini untuk mengetahui faktor-faktor yang mempengaruhi pergerakan Indeks Harga Saham Gabungan, faktor faktor tersebut adalah pergerakan nilai tukar mata uang rupiah terhadap mata uang dolar Amerika Serikat dan inflasi. Penelitian ini menggunakan data pergerakan nilai tukar, inflasi dan IHSG pada bulan terjadinya aksi terorisme tahun 2000 hingga 2018. Analisis data dengan menggunakan regresi linier berganda.Nilai tukar mempunyai pengaruh yang signifikan dan inflasi tidak mempunyai pengaruh.
\end{abstract}

Kata kunci : Kurs, Inflasi, IHSG

\section{Pendahuluan}

Indonesia adalah negara berkembang yang berusaha meningkatkan perekonomiannya agar kesejahteraan dan taraf hidup masyarakat Indonesia meningkat. Agar kesejahteraan dan taraf hidup masyarakat Indonesia meningkat diperlukann perencanaan bertahap agar pertumbuhan ekonomi Indonesia cukup tinggi. Pertumbuhan ekonomi adalah salah satu perkembangan ekonomi yang kegiatannya menghasilkan beberapa pendapatan rill yg berbeda dari waktu ke waktu. Berikut adalah grafik pertumbuhan ekonomi di Indonesia :



Grafik 1. Pertumbuhan Ekonomi Periode 2008-2016

Sumber : www.indonesia-investments.com 
Berdasarkan Grafik 1 Dapat dilihat bahwa pertumbuhan ekonomi mengalami perubahan yang signifikan dari tahun ke tahun. Tahun 2008 terdapat gejala krisis keuangan global sehingga mengubah tatanan perekonomian dunia. Dan Indonesia terkena imbas krisis tersebut terutama menjelang akhir 2008. Grafik 2 membandingkan pertumbuhan ekonomi global, Pertumbuhan ekonomi dinegara maju dan negara berkembang akan selalu mengalami perbedaan.Secara global terjadi penurunan pertumbuhan ekonomi, termasuk pertumbuhan ekonomi negara berkembang juga mengalami penurunan namun kondisi ini jauh lebih baik daripada negara maju, hal ini terlihat pertumbuhan ekonomi Indonesia masih diatas rata-rata pertumbuhan ekonomi dunia, Di tengah perlambatan perekonomian dan berbagai risiko yang dihadapi.

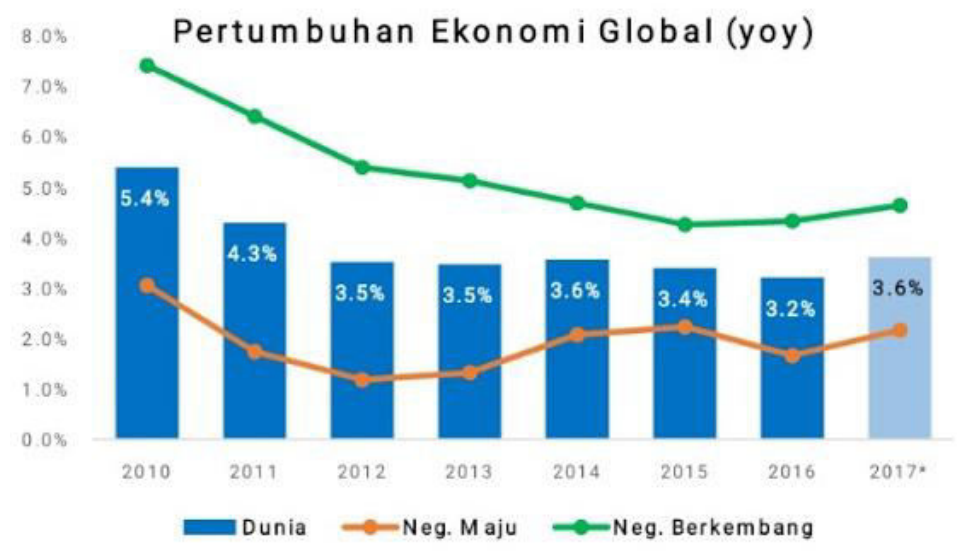

Sumber :www.wordbank.org

Grafik 2. Pertumbuhan Ekonomi Global

Grafik 2 menggambarkan pula adanya perlambatan ekonomi global dimulai sejak tahun 2012, meski terjadi perlambatan terdapat pertumbuhan meskipun dengan angka yang tidak begitu signifikan bahkan pada tahun 2012 dan 2013 terjadi stagnan. Sementara menurut penelitian sejenis menunjukan variabel pertumbuhan ekonomi berpengaruh positif terhadap pertumbuhan bursa efek Indonesia. Berikut adalah grafik pertumbuhan Bursa Efek Indonesia (BEI) periode 2006 hingga 2016 :

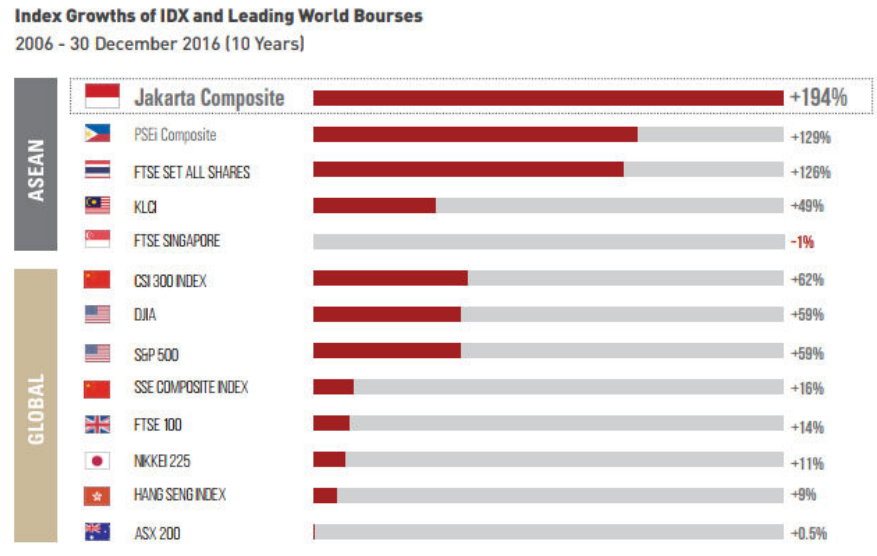

Grafik 3.Index Growths of idx and Leading World Bourses

Sumber :www.worldbank.org

Data pada Grafik 3 menunjukkan pasar modal Indonesia mengalami kemajuan semenjak pemerintah memutuskan untuk menggabungkan Bursa Efek Jakarta (BEJ) dan Bursa Efek Surabaya (BES) menjadi Bursa Efek Indonesia (BEI) atau yang akhirnya dikenal juga dengan Indonesia Stock Exchange (IDX), dari grafik 3 juga diketahui bahwa selama periode 2006 hingga 2016 BEI mampu 
meraih nilai tertinggi diantara bursa-bursa utama dunia dan mencatat pertumbuhan idenx pasar sebanyak 194\% Keadaan pasar modal Indonesia atau Bursa Efek Indonesia menggambarkan situasi perekonomian Indonesia dengan menggunakan indikator indeks harga saham gabungan yang menggambarkan naik turunnya harga saham, makin naik indeks harga saham gabungan maka makin banyak harga-harga saham yang mengalami peningkatan. Harga saham tergantung dari minat beli dan minat jual para investor, minat beli/jual dari para investor dipengaruhi oleh kinerja perusahaan anggota bursa efek dan juga faktor eksternal dari perusahaan seperti situasi politik, ekonomi dan juga kejadiankejadian bencana seperti bencana alam (gempa, tsunami, banjir), bencana non alam (epidemic) dan bencana social (kerusuhan dan terorisme).

Aksi teror yang dilakukan oleh para teroris merupakan suatu tindakan sebagai bentuk kejahatan luar biasa dikarenakan dampak dari kejahatan yang sangat luar biasa dikarenakan dampaknya sangat mempengaruhi banyak hal, yakni memunculkan korban jiwa, dan luka berat yang bersifat masal, kerugian materiel dan stabilitas ekonomi secara nasional serta mempengaruhi penurunan kualitas ekonomi masyarakat dan menjadikan suatu ancaman keamanan dan perdamaian negara. Terorisme merupakan suatu tindakan penyerangan yang terkoordinasi untuk menumbuhkan rasa takut dan cemas terhadap masyarakat. Intinya, terorisme adalah tindakan untuk menumbuhkan rasa takut pada masyarakat tertentu. Para pelaku selalu mengandalkan elemen kejutan yang mengakibatkan korban tidak memiliki kesempatan untuk membela diri. Dengan melihat cakupan dan dampak yang ditimbulkan serta modus operandi yang melampaui kejahatan konvensional, maka tindak pidana terorisme ini dapat dikategorikan sebagai kejahatan luar biasa (extraordinary crime).

Tindakan perbuatan terorisme ini juga dianggap sebagai musuh umat manusia, sehingga perlu penanganan dan langkah yang bersifat luar biasa guna mengungkap dan mencegah tindak pidana tersebut [1]. Peristiwa terorisme sangat merugikan Negara, terutama yang terjadi di Indonesia. Dengan adanya terorisme, pemerintah dipaksa untuk menegakkan hukum secara tegas dengan membuat suatu kebijakan dalam rangka keamanan negara agar tidak terjadi peristiwa serupa di masa yang akan datang. Oleh sebab itu, Tindak pidana terorisme merupakan kejahatan yang bermotif kepentingan dan kebutuhan pribadi atau kelompok. Motif kepentingan dan kebutuhan merupakan fenomena dalam pergaulan antar kelompok untuk mendapatkan kekuasaan atau keuntungan materi, fanatisme kelompok akibat wawasan atau cara berfikir yang sempit dan tertutup. Namun, penindakan melalui upaya paksa dan penangkapan pelaku narapidana terorisme saja tidaklah cukup untuk membuat paham radikal yang melekat pada teroris hilang. Malah justru sebaliknya, narapidana teroris tersebut menyebarkan paham radikal ke dalam lembaga pemasyarakatan dan sangat mempengaruhi narapidana lainnya. Fenomena penyebaran pemahaman radikal dalam lembaga permasyarakatan tidak terlepas dari kondisi Lapas itu sendiri. Menurut Peter R. Neumann, salah satu permasalahan penjara yang menjadi sorotan adalah bahwa penjara memiliki peran besar dalam narasi gerakan radikal militan di era modern.

Aksi terorisme di Indonesia mencuat setelah munculnya kasus Bom Bali I pada 12 Oktober 2002, tepatnya di Sari's Club dan Paddy's Club Kuta Bali yang tercatat \pm 202 orang tewas dan 300 orang terluka, kemudian tragedi pemboman Hotel JW Marriot dan Ritz-Carlton, Jumat 17 juli 2009 yang menewaskan 9 orang dan mencederai puluhan lainnya. Hal ini menegaskan bahwa betapa teror tidak pernah berhenti mengancam, sedikit saja lalai atau lengah dalam mengantisipasi maka terorisme akan datang membawa bencana dan kerugian masif. Tentu saja, serangkaian tragedi ini merupakan pukulan dahsyat bagi Bangsa Indonesia. Terorisme selalu identik dengan teror, kekerasan, ekstriminitas dan intimidasi sehingga seringkali menimbulkan konsekuensi negatif bagi masyarakat dan menjatuhkan banyak korban. Seperti yang telah diketahui peristiwa yang telah terjadi di Indonesia akan sangat berpotensi memberikan dampak negatif bagi iklim investasi dan ekonomi, seiring adanya indikasi ketidakstabilan politik dan keamanan dalam negeri. Pergerakan performa IHSG selama terjadi aksi terorisme berlangsung lebih sering terjadi penurunan tergambar pada grafik 4 terutama pada tahun 2002 saat bom Bali 1. 




Grafik 4 Performa IHSG selama terjadi aksi terorisme Sumber: www.yahoo.finance, data diolah

Grafik 4 memperlihatkan gerakan fluktuatif dari performa IHSG saat kejadian aksi terorisme dengan kecenderungan adanya penurunan dari IHSG saat kejadian aksi terorisme. Nilai tukar rupiah mengalami fluktiasi terhadap dollar amerika serikat saat terjadnya peristiwa terorisme terlihat pada grafik 5. Nilai tukar rupiah terhadap dolar Amerika Serikat mempunyai pengaruh yang signifikan terhadap IHSG [2]

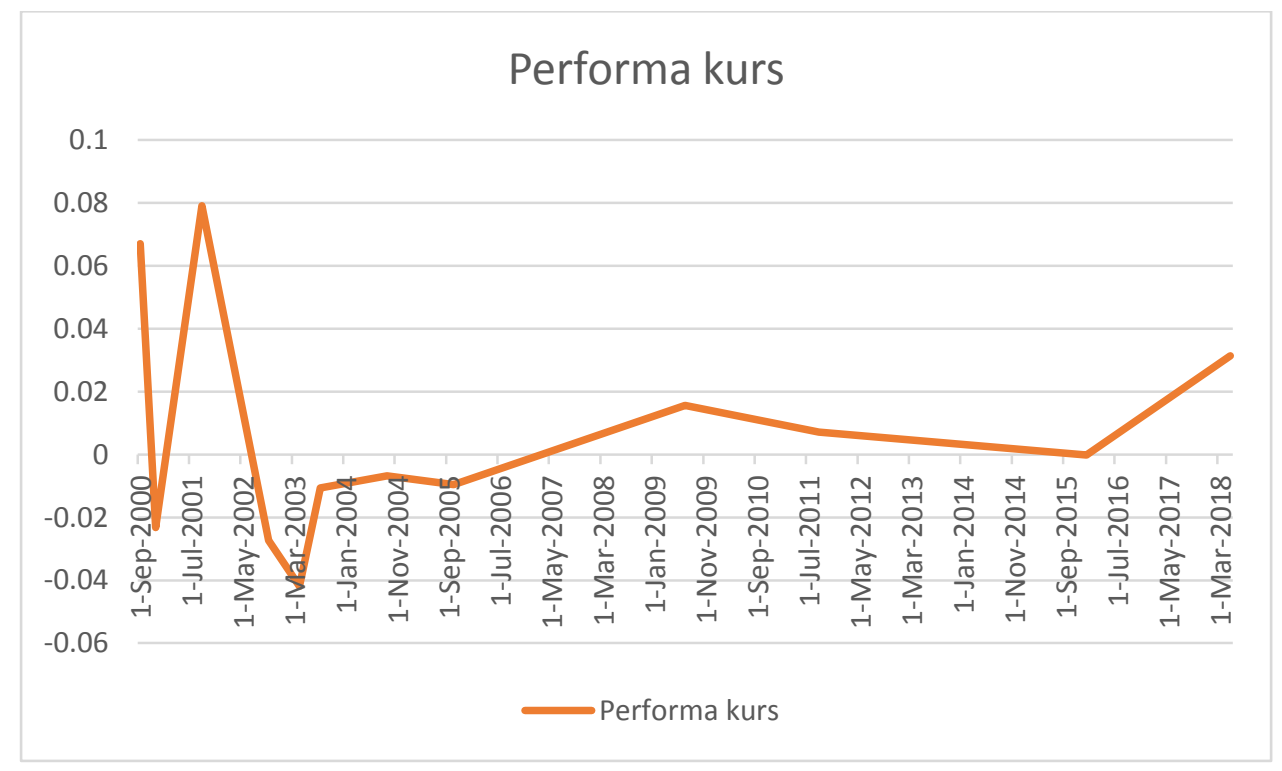

Grafik 5 performa kurs selama terjadi aksi terorisme

Sumber: investing.com, data diolah

Grafik 5 memperlihatkan performa nilai tukar rupiah terhadap dolar Amerika Serikat pada Maret 2003 terjadi penurunan yang lebih besar dibandingkan dengan penurunan pada kejadian aksi terorisme di Bulan yang berbeda. 


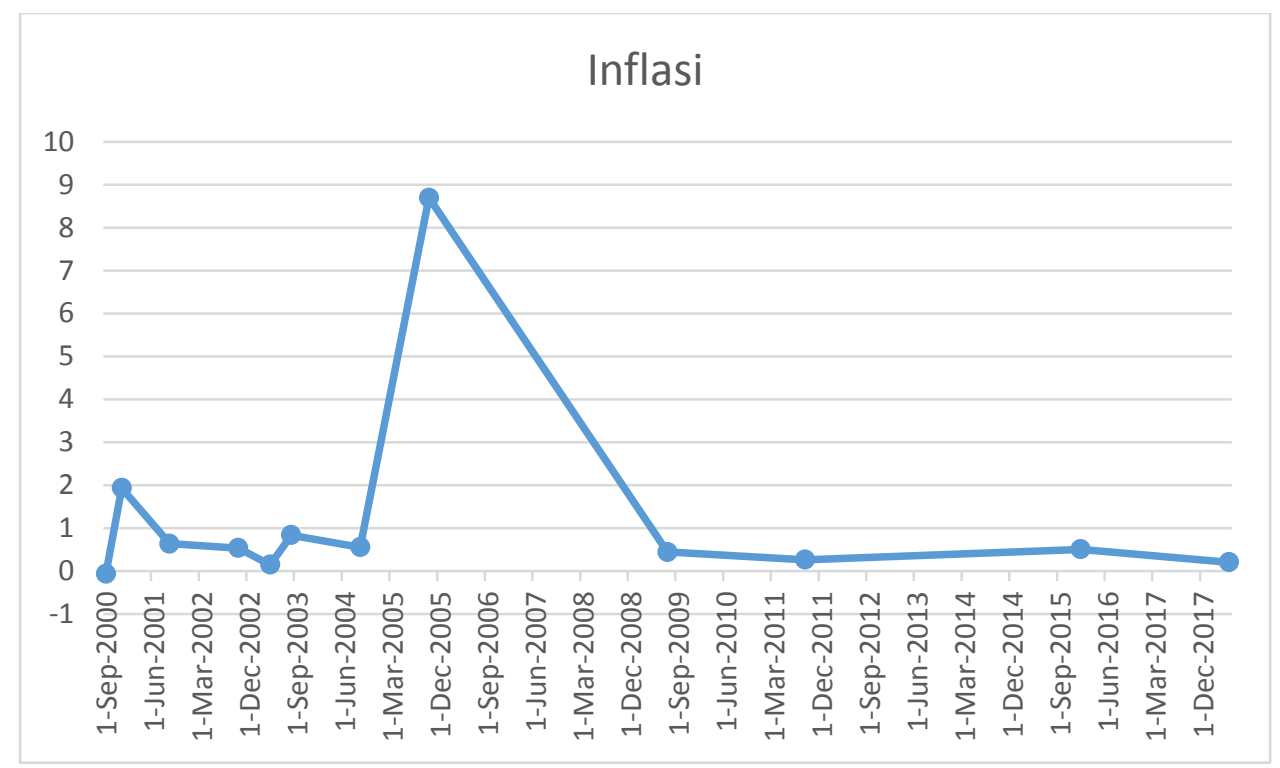

Grafik 6 Inflasi selama aksi terorisme

Sumber: kemendag, data diolah

Grafik 6 Inflasi yang memiliki pengaruh signifikan terhadap Indeks Harga Saham Gabungan (IHSG) sedangkan nilai tukar/kurs (USD/IDR) tidak memiliki pengaruh signifikan terhadap Indeks Harga Saham Gabungan (IHSG) [2]

\section{- Inflasi}

Inflasi adalah kecenderungan kenaikan harga barang-barang yang bersifat umum dan terjadi secara terus-menerus [3]. Inflasi memiliki dampak positif dan negatif tergantung tinggi atau tidaknya inflasi. Bilamana inflasi yang terjadi adalah rendah justru mempunyai pengaruh yang positif dalam arti dapat mendorong perekonomian ke arah lebih baik namun jika inflasi terlalu tinggi maka akan meyebabkan kekacauan. Tingkat inflasi yang tinggi biasanya dikaitkan dengan kondisi ekonomi yang overheated.

\section{- Kurs}

Kurs merupakan harga suatu mata uang relatif terhadap mata uang negara lain [4]. Kurs memainkan peranan penting dalam keputusan pembelanjaan karena kurs memungkinkan untuk menerjemahkan harga-harga dari berbagai negara ke dalam suatu bahasa yang sama. Jika diasumsikan semua kondisi lain tetap, maka depresiasi mata uang dari suatu negara terhadap segenap mata uang lainnya (kenaikan harga valuta asing bagi negara yang bersangkutan) menyebabkan ekspornya lebih murah dan impor yang lebih mahal. Sedangkan apresiasi (penurunan harga valuta asing di negara yang bersangkutan) membuat ekspornya lebih mahal dan impor lebih murah.

\section{- Indeks Harga Saham}

Indeks harga saham adalah indikator yang menunjukkan pergerakan harga saham. Pergerakan indeks menunjukkan kondisi pasar waktu ke waktu, apakah harga saham sedang naik atau turun. Indeks harga saham menjadi indikator bagi investor untuk pengambilan keputusan investasi. Indeks harga saham adalah Indeks harga saham adalah suatu indikator yang menunjukkan pergerakan harga saham [5]. Indeks berfungsi sebagai indikator tren pasar, artinya pergerakan indeks menggambarkan kondisi pasar pada suatu saat, apakah pasar aktif atau lesu. Indeks harga saham adalah indikator yang memperlihatkan pergerakan harga saham dan menggambarkan kondisi pasar apa aktif atau lesuh, dan indeks harga saham dipakai investor untuk mengambil keputusan dalam berinvestasi. 
Metode penelitian yang peneliti gunakan dalam penelitian ini adalah metode penelitian ekspanatori. Populasi penelitian ini adalah seluruh kejadian serangan bom yang dilakukan oleh teroris yang berjumlah 12 kejadian, dimulai dari tahun 2000 hingga tahun 2018. Metode analisis yang digunakan adalah analisis regresi berganda dengan menggunakan alat analisis yaitu SPSS.

\section{Analisis Regresi Berganda}

Pada penelitian ini, metode yang digunakan adalah metode regresi berganda yang merupakan pengembangan dari analisis regresi sederhana, hal ini dikarenakan variable bebas yang digunakan lebih dari satu variable. Kegunaan dari analisis regresi berganda ini adalah untuk memperkirakan nilai dari variable Y yaitu IHSG apabila dipengaruhi oleh oleh dua variable bebasnya, yaitu Kurs dan Inflasi. Adapun persamaan regresi berganda untuk penelitian ini adalah:

$$
\mathrm{IHSG}=\alpha+\beta 1 \mathrm{KURS}+\beta 2 \mathrm{INF}+\mathrm{e}
$$



\section{Pengujian Hipotesis}

Pengujian hipotesis pada penelitian ini adalah:

\section{a. Uji T}

Kegunaan dari uji t adalah untuk mengetahui pengaruh secara signifikan antara variable independen dengan variable dependen secara parsial. Hasil dari penelitian akan menunjukan hasil yang signifikan apabila t-table < alpha yang ditetapkan yaitu 5\%. Sehingga pengujian pada penelitian ini adalah untuk mengetahui pengaruh antara inflasi terhadap IHSG dan pengaruh antara kurs terhadap IHSG.

\section{b. Uji F}

Uji $\mathrm{F}$ digunakan untuk mengetahui pengaruh secara bersama-sama antara setiap variable independen terhadap variable dependen. Pengujian ini menggunakan uji signifikansi dua arah dengan alpha 5\%. Apabila nilai signifikansi $<5 \%$, maka dapat disimpulkan terdapat pengaruh secara bersama-sama antara variable dependen dengan variable independen. Pengujian pada penelitian ini adalah untuk mengetahui apakah terdapat pengaruh secara bersama-sama antara variable inflasi dan kurs terhadap IHSG.

\section{Hasil Penelitian Dan Pembahasan}

\section{Analisis Deskriptif}

Serangan terorisme di Indonesia dimulai sejak terjadinya penyerangan bom di gedung Bursa Efek Indonesia di Jakarta. Sejak saat itu telah terjadi serangkaian serangan bom diberbagai daerah di Indonesia hingga yang terakhir terjadi pada tahun 2018. Peristiwa ini tentu saja akan memberikan dampak yang negative bagi investasi dan perekonomian di Indonesia. Serangan terorisme akan menyebabkan adanya ketidakpercayaan dari para investor dan calon investor mengenai perekenomian di Indonesia. Keraguan ini muncul apakah dana yang mereka tanamkan di berbagai perusahaan di Indonesia akan memberikan pengembalian seperti yang mereka harapkan. Menurut hasil Riset CNBC 
Indonesia, hampir seluruh peristiwa ledakan bom di Indonesia menyebabkan terkoreksinya IHSG (Indeks Harga Saham Gabungan)

Tabel 1. Dampak aksi teror selama periode 2000-2018

\begin{tabular}{|c|c|c|c|c|c|}
\hline Tgl Kejadian & Keterangan & $\begin{array}{l}\text { Korban } \\
\text { jiwa }\end{array}$ & $\begin{array}{l}\text { Korban } \\
\text { luka-luka }\end{array}$ & $\begin{array}{l}\text { Performa } \\
\text { Rupiah }\end{array}$ & $\begin{array}{l}\text { Performa } \\
\text { IHSG }\end{array}$ \\
\hline 13-Sep-2000 & $\begin{array}{l}\text { Bom Bursa Efek } \\
\text { Jakarta }\end{array}$ & 10 & 90 & $-1.68 \%$ & $-7.02 \%$ \\
\hline 24-Dec-2000 & Bom Malam Natal & 16 & 96 & $-1.51 \%$ & $-1.47 \%$ \\
\hline 23-Sep-2001 & Bom Plaza Atrium & & 6 & $-0.37 \%$ & $-0.97 \%$ \\
\hline 12-Oct-2002 & Bom Bali I & 202 & 300 & $-3.31 \%$ & $-10.36 \%$ \\
\hline 27-Apr-2003 & $\begin{array}{l}\text { Bom Bandara Soetta } \\
\text { Terminal 2F }\end{array}$ & & 10 & & $-0.95 \%$ \\
\hline 5-Aug-2003 & Bom JW Marriott & 11 & 152 & $-1.35 \%$ & $-3.06 \%$ \\
\hline 9-Sep-2004 & $\begin{array}{l}\text { Bom Kedubes } \\
\text { Australia }\end{array}$ & 5 & 100 & $-0.09 \%$ & $-0.82 \%$ \\
\hline 1-Oct-2005 & Bom Bali II & 23 & 196 & $-0.05 \%$ & $0.38 \%$ \\
\hline 17-Jul-2009 & $\begin{array}{l}\text { Bom Jakarta } 2009 \\
\text { (Hotel JW Marriot \& } \\
\text { Ritz Carlton) }\end{array}$ & 9 & 50 & $-0.49 \%$ & $-0.55 \%$ \\
\hline 25-Sep-2011 & $\begin{array}{l}\text { Bom Bunuh Diri di } \\
\text { GBIS Kepunton Solo }\end{array}$ & 28 & 1 & $-3.19 \%$ & $-3.22 \%$ \\
\hline 14-Jan-2016 & $\begin{array}{l}\text { Bom dan Baku } \\
\text { Tembak di Sarinah } \\
\text { Jakarta }\end{array}$ & 8 & 24 & $-0.61 \%$ & $-0.53 \%$ \\
\hline 13-May-2018 & $\begin{array}{l}\text { Bom bunuh diri di } \\
\text { Gereja Surabaya }\end{array}$ & 13 & 41 & $-0.09 \%$ & $-0.16 \%$ \\
\hline
\end{tabular}

Sumber: Kajian Tim Riset CNBC Indonesia

Berikut ini merupakan hasil perhitungan statistik deskriptif dengan menggunakan SPSS:

Tabel 2 Statistik Deskriptif

\begin{tabular}{|l|r|r|r|r|r|}
\hline & N & \multicolumn{1}{|c|}{ Minimum } & Maximum & \multicolumn{1}{c|}{ Mean } & Std. Deviation \\
\hline Kurs & 12 & 8.485 & 13.895 & 9.95517 & 1.733164 \\
Inflasi & 12 & -.06 & 8.70 & 1.2292 & 2.40548 \\
IHSG & 12 & -.128337 & .037948 & $-3.35340015 \mathrm{E}-2$ & .050714807 \\
Valid N (listwise) & 12 & & & & \\
\hline
\end{tabular}

Sumber: Olah Data SPSS, 2019

Berdasarkan table 2. Statistik Deskriptif, maka dapat dilihat bahwa nilai terendah dari IHSG adalah sebesar -0.128337 , sedangkan nilai tertinggi sebesar 0.037948. Rata-rata nilai IHSG adalah 3.353400 dengan standar deviasi 0.050714807 . Hal ini menunjukan sebaran nilai yang kecil pada variable IHSG karena nilai standar deviasi lebih kecil dari nilai rata-ratanya. Sedangkan untuk variable 
kurs nilai terendahnya adalah 8.485 dan nilai tertingginya adalah 13.895 . untuk rata-rata nilai variable kurs sebesar 9.955 dan standar deviasi 1.733. hal ini mengindikasikan sebaran yang rendah karena nilai standar deviasi lebih kecil dari nilai rata-ratanya. Untuk variable inflasi angka minimumnya adalah -0.6 dan angka maksimumnya adalah

8.7 dengan nilai rata-rata 1.23 serta standar deviasi 2.4. Hal ini justru menunjukan hasil yang berbeda, karena nilai standar deviasinya lebih besar dari nilai rata-ratanya.

\section{Analisis Regresi Berganda}

Tabel 3 memperlihatkan hasil pengolahan data regresi berganda dengan menggunakan SPSS:

Tabel 3 Analisis Regresi Berganda

Coefficients

\begin{tabular}{|c|c|c|c|c|c|}
\hline \multirow[b]{2}{*}{ Model } & \multicolumn{2}{|c|}{ Unstandardized Coefficients } & \multirow{2}{*}{$\begin{array}{c}\text { Standardized } \\
\text { Coefficients } \\
\text { Beta }\end{array}$} & \multirow[b]{2}{*}{$\mathrm{t}$} & \multirow[b]{2}{*}{ Sig. } \\
\hline & $\mathrm{B}$ & Std. Error & & & \\
\hline 1 (Constant) & 1.167 & .088 & & -1.901 & .090 \\
\hline Kurs & .013 & .009 & .458 & 1.545 & .157 \\
\hline Inflasi & .015 & .006 & -.005 & -.018 & .986 \\
\hline
\end{tabular}

a. Dependent Variable: IHSG

Sumber: Data diolah.

Model regresi penelitian yang dihasilkan dari tabel 3 adalah sebagai berikut :

$$
\mathrm{IHSG}=1,167+0,013 \mathrm{KURS}+0,015 \mathrm{INF}+\mathrm{e}
$$

Model regresi penelitian menunjukkan bahwa:

a. Nilai konstanta sebesar 1.167 mempunyai arti bila kurs dan Inflasi nilainya sama dengan nol maka IHSG nilainya positif yaitu sebesar 1.167

b. Koefisien variabel Kurs sebesar 0.13 mempunyai tanda positif artinya bila variabel kurs menambah nilainya sebesar 1 point maka IHSG mengalami kenaikan senilai 0.013 dengan asumsi variabel inflasi konstan.

c. Koefisien variabel inflasi sebesar 0.015 mempunyai tanda positif artinya bila variabel inflasi menambah nilainya sebesar 1 point maka IHSG mengalami kenaikan sebesar 0.015 dengan asumsi variabel kurs konstan.

\section{Koefisien Determinasi}

Tabel 4 memberikan gambaran mengenai hasil perhitungan koefisien determinasi dengan menggunakan SPSS:

Tabel 4 Koefisien Determinasi

Model Summary

\begin{tabular}{|l|r|r|r|r|r|}
\hline Model & R & R Square & Adjusted R Square & $\begin{array}{c}\text { Std. Error of the } \\
\text { Estimate }\end{array}$ & Durbin-Watson \\
\hline 1 & $.458^{\mathrm{a}}$ & .410 & .434 & .049843433 & 1.133 \\
\hline
\end{tabular}

a. Predictors: (Constant), Inflasi, Kurs

b. Dependent Variable: IHSG

Sumber: Data diolah. 2019 
Hasil uji koefisien determinasi $\mathrm{R}^{2}$ sebesar 0.410 (41\%) dan adjusted $R$ Square sebesar 0,434 $(43,4 \%)$. Varibel kurs dan variabel inflasi memberikan pengaruh kepada variabel IHSG sebesar 43,4\% sedangkan 56,6\% dipengaruhi oleh variabel-variabel lain yang tidak diteliti pada penelitian ini.

\section{Pengujian Hipotesis Parsial (Uji t)}

Tabel 5 menunjukkan hasil perhitungan uji t dengan menggunakan SPSS:

Tabel 5 Uji t

\begin{tabular}{|c|c|c|c|c|c|}
\hline \multirow[b]{2}{*}{ Model } & \multicolumn{2}{|c|}{ Unstandardized Coefficients } & \multirow{2}{*}{$\begin{array}{c}\text { Standardized } \\
\text { Coefficients } \\
\text { Beta }\end{array}$} & \multirow[b]{2}{*}{$t$} & \multirow[b]{2}{*}{ Sig. } \\
\hline & $B$ & Std. Error & & & \\
\hline 1 (Constant) & 1.167 & .088 & & -1.901 & .090 \\
\hline Kurs & .013 & .009 & .458 & 1.545 & .007 \\
\hline Inflasi & .015 & .006 & -.005 & -.018 & .136 \\
\hline
\end{tabular}

a. Dependent Variable: IHSG

Sumber: Data diolah. 2019

Uji t dengan menggunakan $\alpha=5 \%$ (two tailed) dan $\mathrm{df}=\mathrm{n}-\mathrm{k}-1$, dimana $\mathrm{n}$ merupakan jumlah sampel dan $\mathrm{k}$ merupakan jumlah variabel bebas. Hasil perhitungan adalah sebagai berikut variabel bebas Kurs mempunyai nilai $t$ hitung $=1,545$, sehingga $t$ hitung $<\mathrm{t}$ tabel dan nilai sig sebesar 0.007 , maka dapat disimpulkan untuk menolak Ho dan menerima Ha, yang berarti variabel Kurs mempunyai pengaruh yang signifikan terhadap variabel IHSG. Variabel bebas Inflasi mempunyai nilai t hitung = 0,018 dimana t hitung > $\mathrm{t}$ dan nilai sig. sebesar 0.136, maka dapat disimpulkan untuk menerima Ho dan menolak Ha, yang berarti variabel inflasi tidak mempunyai pengaruh yang signifikan terhadap variabel IHSG.

\section{Pengujian Hipotesis Simultan (Uji F)}

Tabel 6 merupakan hasil perhitungan uji F dengan menggunakan SPSS:

Tabel 6 Uji F

\begin{tabular}{|c|c|c|c|c|c|c|}
\hline \multicolumn{7}{|c|}{ ANOVA $^{b}$} \\
\hline & & Sum of Squares & $\mathrm{Df}$ & Mean Square & $\mathrm{F}$ & Sig. \\
\hline \multirow[t]{3}{*}{1} & Regression & .006 & 2 & .003 & 1.194 & $.002^{\mathrm{a}}$ \\
\hline & Residual & .022 & 9 & .002 & & \\
\hline & Total & .028 & 11 & & & \\
\hline
\end{tabular}

a. Predictors: (Constant), Inflasi, Kurs

b. Dependent Variable: IHSG

Sumber: Olah Data SPSS, 2018

Uji $\mathrm{F}$ dengan menggunakan $\alpha=5 \%$ dan $\mathrm{df}_{1}=\mathrm{k}-1$ dan $\mathrm{df}_{2}=\mathrm{n}-\mathrm{k}, \mathrm{n}$ merupakan jumlah sampel dan $\mathrm{k}$ merupakan jumlah keseluruhan variabel. Dari tabel 6 di atas dapat diketahui bahwa nilai sig.sebesar 0.002, maka dapat disimpulkan bahwa variabel bebas kurs dan variabel bebas inflasi secara bersama-sama mempunyai pengaruh yang signifikan terhadap pergerakan nilai IHSG. 


\section{Kesimpulan}

Kejadian terror bom di Indonesia sejak tahun 2000 hingga tahun 2018 telah menyebabkan korban jiwa meninggal dan korban luka-luka yang tidak sedikit. Selain korban jiwa dan kerusakan infrastuktur, serangan terror di Indonesia juga menyebabkan terkoreksinya nilai IHSG, pelemahan nilai tukar dan meningkatnya inflasi. Hasil penelitian menunjukan bahwa secara bersama-sama terdapat pengaruh antara nilai tukar dengan inflasi terhadap IHSG sebesar $43.4 \%$, sedangkan sisanya dipengaruhi oleh variable lain yang tidak diteliti. Hasil penelitian juga menunjukan bahwa secara parsial terdapat pengaruh antara variable nilai tukar dengan performa IHSG, sedangkan inflasi tidak mempengaruhi performa IHSG.

\section{Ucapan Terima Kasih (Acknowledgement)}

Ucapan terima kasih kepada Direktorat Riset dan Pengabdian Masyarakat Direktorat Jenderal Penguatan Riset dan Pengembangan Kementerian Riset, Teknologi, dan Pendidikan Tinggi yang telah membiayai penelitan tersebut. Dengan Kontrak Penelitian Nomor: 110/SP2H/PPM/DRPM/2019, tanggal 8 Maret 2019

\section{Daftar Pustaka}

[1] Ali Masyar, Gaya Indonesia Menghadapi Terorisme: Sebuah Kritik Kebijakan Hukum Pidana Terorisme di Indonesia, Mandar Maju, Bandung, 2009.

[2] Kewal, SS. 2012. Pengaruh Inflasi, Suku Bunga, Kurs, dan Pertumbuhan PDB Terhadap Indeks

[3] Harga Saham Gabungan. Jurnal Economia, Volume 8, Nomor 1, April 2012 hal 53-64

[4] Murni, A. 2016. Ekonomika Makro. Edisi Revisi. Bandung : Refika Aditama

[5] Ekananda, Mahyus. 2014. Ekonomi Internasional. Jakarta : Erlangga

[6] Martalena \& Maya Malinda .(2011). Pengantar Pasar Modal. Edisi Pertama, Penerbit Andi: yogyakarta 